\title{
Evaluation of an Aeroponics System to Screen Maize Genotypes for Resistance to Fusarium graminearum Seedling Blight
}

\author{
Lindsey J. du Toit, Graduate Research Assistant, H. Walker Kirby, Associate Professor, and Wayne L. Pedersen, \\ Associate Professor, Department of Plant Pathology, University of Illinois at Urbana-Champaign, Urbana 61801
}

\begin{abstract}
du Toit, L. J., Kirby, H. W., and Pedersen, W. L. 1997. Evaluation of an aeroponics system to screen maize genotypes for resistance to Fusarium graminearum seedling blight. Plant Dis. $81: 175-179$

A noncirculating aeroponics system was evaluated as a method for rapid screening of maize genotypes for resistance to Fusarium graminearum seedling blight/root rot. The system allows for nondestructive, repetitive sampling of seedlings for assessing disease progress and seedling growth. Shoot growth and root rot were assessed at 3-day intervals, and final shoot and root dry weight were determined 15 days after inoculation. The nine hybrids screened differed in severity of root rot as early as 6 days after inoculation, indicating differences in resistance to $F$. graminearum. Inoculation did not always significantly affect shoot growth, root dry weight, or shoot dry weight, but differences in these agronomic traits were observed among hybrids. LH119 $\times$ LH51 and Pioneer Brand 3379 showed the greatest resistance to root rot. Area underdisease progress curve and a critical stage of disease assessment ( 9 days after inoculation) gave similar rankings of hybrids for root rot resistance, indicating that a single disease assessment (versus multiple assessments) may be adequate in screening for resistance with this aeroponics system.
\end{abstract}

Seed germination and seedling establishment are critical periods in the life cycle of a plant. This is particularly true for maize (Zea mays L.), which makes little compensation for over- or under-planting (10). Maize seed rots and seedling blights are significant problems in localized areas every year (22). Kernels may be attacked by soilborne or seed-borne pathogens, resulting in seed rots, or pre- or post-emergence seedling blights. Infected seedlings may die or develop into less vigorous plants (21).

Various methods have been employed to control seed rots and seedling blights. Use of high quality seed, good cultural practices, and fungicide seed treatments are important control practices $(7,8,21,22)$, but cannot always protect against seedling blights under adverse environmental conditions. Rapid seedling emergence and resistance to seedling blights are heritable characteristics that can be incorporated into lines with suitable agronomic characteristics (22). Diverse methods have been developed to screen genotypes for resistance $(1,7,10-12,14,16,18)$. Reduced stand counts relative to noninoculated control treatments are a simple and widely used

Corresponding author: L. J. du Toit

E-mail: t-du@students.uiuc.edu

Accepted for publication 4 November 1996.

Publication no. D-1996-1217-04R

(C) 1997 The American Phytopathological Society parameter to screen for resistance. However, stand counts are affected by environmental and cultural factors that are typically difficult to control under field conditions. In addition, aboveground symptoms of seedling blights are not highly characteristic, as they closely resemble symptoms caused by insect damage and mechanical or chemical injury. For this reason, Campbell and Noe (3) recommended that root samples from symptomatic and asymptomatic plants be assayed to verify the suspected cause of foliar symptoms.

One of the problems with assessing disease on root systems is the use of destructive sampling techniques. The same seedlings cannot be evaluated at later stages to determine disease progress, nor can they be used for cross- or self-pollination in breeding for resistance. Hooker and Dickson (12) developed a screening test, using excised corn embryos, that enabled greater precision in genotype evaluation and assessment of disease development over time. An unconventional technique that overcomes the limitation of destructive sampling is aeroponics, in which the roots are suspended and misted with a nutrient solution. Wagner and Wilkinson (23) developed an aeroponics system to enable nondestructive examination of disease development on soybean taproots inoculated with Phytophthora sojae M. J. Kaufmann \& J. W. Gerdemann. The system used a noncirculating nutrient solution to prevent buildup of secondary inoculum that would affect disease development. It enabled di- rect and nondestructive access to the roots for repetitive measurement of lesion development. Other aeroponics systems have been developed and tested for a range of uses on different plant types $(4,20,25)$.

Fusarium graminearum Schwabe causes seed rot and seedling blight of maize as well as root rot, stalk rot, and ear rot (15, $19,21,22)$. It is a serious pathogen of other graminaceous hosts, particularly wheat (2), and has become increasingly important in areas where maize is grown in rotation with wheat (24). The fungus is cosmopoli$\tan$ in distribution and can produce an array of mycotoxins (15).

The objective of this experiment was to examine the aeroponics system developed by Wagner and Wilkinson (23) as a rapid and preliminary method of screening maize genotypes for resistance to $F$. graminearum seedling blight/root rot.

\section{MATERIALS AND METHODS}

Aeroponics system. The aeroponics system consisted of a root misting chamber, solenoid valve, electronic time clock, stainless steel canister, and pressurized air supply (23). Three chambers were placed on a greenhouse bench with four $240-\mathrm{cm}$ fluorescent lamps (Sylvania Greenhouse Lighting, St. Louis, MO) providing an additional $23.2 \mu \mathrm{E} \quad \mathrm{s}^{-1} \mathrm{~m}^{-2}$ supplemental lighting. Modified, half-strength Hoagland and Arnon nutrient solution (9) was stored in 20-liter stainless steel canisters (Firestone Steel Products Co., Spartanburg, SC) pressurized to approximately $552 \mathrm{kPa}$ with a greenhouse air supply system. An electronic timer was set to mist roots $1 \mathrm{~s}$ every 15 min to keep roots moist and turgid.

Seedling and inoculum preparation. Nine maize hybrids were selected on the basis of their popularity in the Corn Belt of the U.S., reported resistance or susceptibility to Fusarium spp., and/or morphology of the root system (Table 1). Seed of each hybrid was surface disinfected in sodium hypochlorite $(0.05 \%)$ for 90 to $120 \mathrm{~s}$ and then rinsed in distilled water three times. Coarse-grade vermiculite mixed with water $(2,000: 750, \mathrm{vol} / \mathrm{vol})$ was placed in plastic germination boxes. Seed was placed on the vermiculite and covered with a second layer of moistened vermiculite. Germination boxes were set on a greenhouse bench and covered for 3 days. The vermiculite was sprinkled with tap water daily. Sevento 10-day-old seedlings were washed free of vermiculite prior to inoculation. 
A mycelial suspension was prepared by blending one 30- to 40-day-old potato dextrose agar (PDA) plate of $F$. graminearum in $800 \mathrm{ml}$ of distilled water for $20 \mathrm{~s}$. Each seedling was inoculated by dipping mesocotyl) into the mycelial suspension for $10 \mathrm{~s}$. For noninoculated treatments, seedlings were dipped into a PDA suspension prepared in the same manner as the into a root misting chamber where it was supported by a polyurethane foam plug placed around the lower stem. Foam plugs were prepared as described by Wagner and Wilkinson (23) to remove phytotoxins and to facilitate insertion of the seedling into the plug.

Disease assessment. Seedlings were examined for growth and disease development at 3-day intervals from zero to 15 days after transplanting. At each interval, shoot height was measured and roots rated the root system (including kernel and inoculum. Each seedling was transplanted

for disease. The rating system was a modification of the scale described by Hooker (11) in which $0=0 \% ; 1=1$ to $25 \% ; 2=26$ to $50 \% ; 3=51$ to $75 \% ; 4=76$ to $100 \%$ root discoloration/rotting; $5=$ root system dead and fragmented; and $6=$ whole seedling dead (Fig. 1). Only seminal roots and the mesocotyl were rated, as nodal roots tend to outgrow infection by $F$. graminearum (18). Fifteen days after transplanting, root and shoot dry weight were measured by oven drying for approximately 72 $\mathrm{h}$ at $100 \pm 5^{\circ} \mathrm{C}$. Nodal roots were removed prior to oven drying because they were not included in root disease assessment.

Experimental design. The experiment used a split plot design with three chambers serving as replications. Each chamber was divided into two main plots, inoculated and noninoculated treatments, separated by a row of foam plugs. Two seedlings (experimental unit) per hybrid (split plot) were arranged randomly within main

Table 1. Characteristics of nine maize hybrids selected to screen for resistance to Fusarium graminearum seedling blight

\begin{tabular}{|c|c|c|}
\hline Hybrid & Hybrid source & Characteristics $^{\mathbf{a}}$ \\
\hline 3378 & Pioneer & Large root system; partial resistance to Fusarium \\
\hline 3379 & Pioneer & $\begin{array}{l}\text { High yields; smaller roots; less resistance to root } \\
\text { rots }\end{array}$ \\
\hline LH136 × LH82 & Holden Foundation Seeds & $\begin{array}{l}\text { Widely grown in the Corn Belt; high yields; LH82 } \\
\text { lines are less resistant to Fusarium }\end{array}$ \\
\hline LH119 × LH51 & Holden Foundation Seeds & $\begin{array}{l}\text { Widely grown in the Corn Belt; large root system; } \\
\text { high yields }\end{array}$ \\
\hline LH123 × LH93 & Holden Foundation Seeds & Large root system, especially under moisture stress \\
\hline 7997 & Cargill & Widely grown; high yields; unknown resistance \\
\hline DK667 & DeKalb & Widely grown; high yields; unknown resistance \\
\hline A6550 & Akin Seeds & Similar characters to LH1 $23 \times$ LH93 \\
\hline LH204 × LH212 & Holden Foundation Seeds & $\begin{array}{l}\text { Newer, increasingly grown hybrid; unknown re- } \\
\text { sistance }\end{array}$ \\
\hline
\end{tabular}

${ }^{a}$ Characteristics described according to W. L. Pedersen (personal communication).
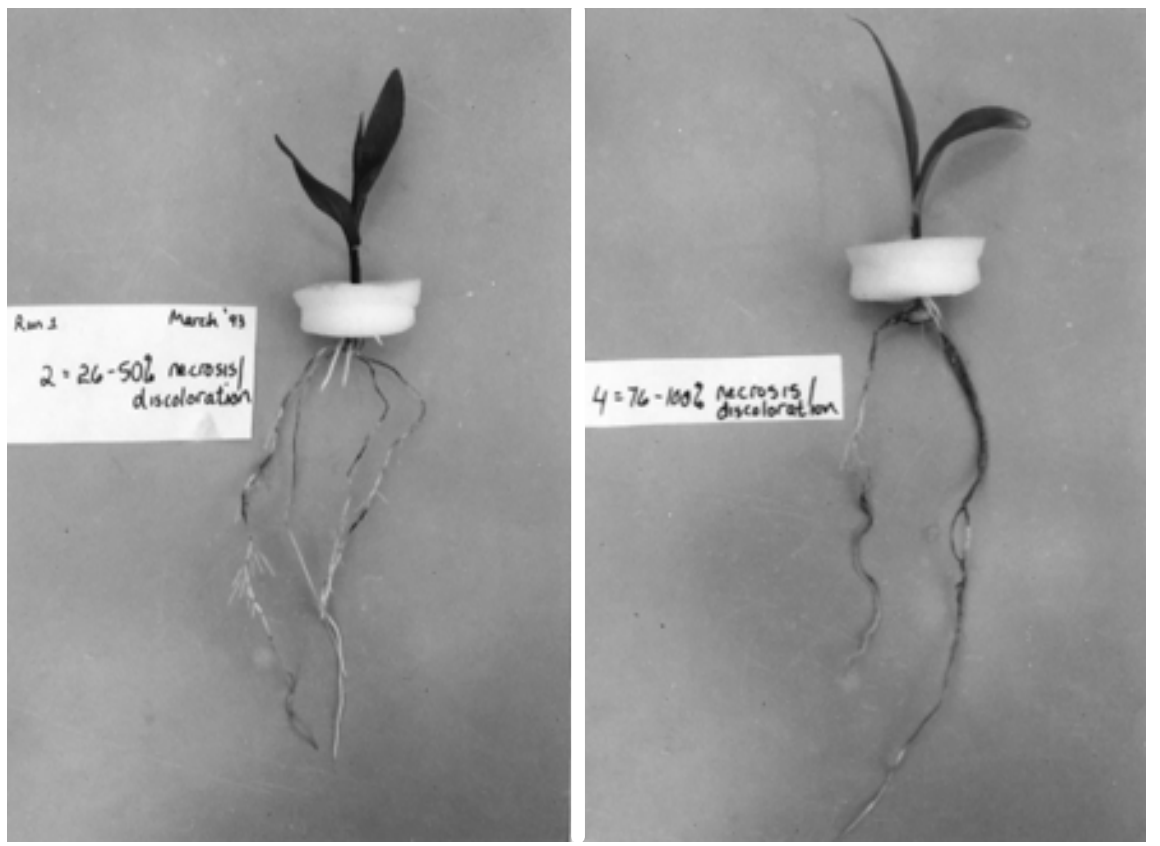

Fig. 1. Maize seedlings inoculated with Fusarium graminearum and grown in an aeroponics system: seedling on the left with a root rot rating of 2; seedling on the right with a root rot rating of 4 , based on a rating scale modified from Hooker (11). plots. The entire experiment was conducted three times: experiment 1 was initiated on 12 March 1993, experiment 2 on 31 March 1993, and experiment 3 on 3 March 1994. Data for root disease, shoot growth, root dry weight, and shoot dry weight were analyzed by SAS GLM procedures (SAS Institute, Cary, NC). Areaunder disease progress curve (AUDPC) and area under shoot growth curve (AUSGC) were determined for root rot rating and shoot growth measurements, respectively, for each hybrid. Data for the three experiments were analyzed separately because of significant variation among experiments. Fisher's protected least significant difference (LSD) $(P \leq 0.05)$ was used to separate means of inoculated seedlings by hybrid. Pearson's correlation coefficients were calculated for AUDPC, AUSGC, root dry weight, and shoot dry weight for all three experiments.

\section{RESULTS}

Differences among hybrids were observed for AUDPC, AUSGC, root dry weight, and shoot dry weight. Hybrids differed in root rot susceptibility in all three experiments (Table 2). Root disease for inoculated seedlings ranged from an AUDPC value of 13.25 (LH119 $\times$ LH51) to 41.25 (A6550) in experiment 1 , from 19.25 (LH119 $\times$ LH51) to 42.00 (LH123 $\times$ LH93) in experiment 2, and from 15.75 $($ LH119 $\times$ LH51) to 29.25 (LH123 $\times$ LH93) in experiment 3 (Table 2). Rankings of hybrids for root rot resistance based on AUDPC were consistent over the three experiments for the more susceptible hybrids LH123 x LH93 and A6550, and for the more resistant hybrids LH119 $\times$ LH51 and Pioneer Brand 3379, but rankings varied for hybrids with intermediate levels of resistance (Table 2).

Significant differences in root rot among hybrids were observed as early as 6 days after inoculation (DAI) (Fig. 2). Disease development was most rapid between 3 and 9 DAI. Greatest differentiation among hybrids occurred 9 to $15 \mathrm{DAI}$, therefore 9 DAI could be selected as the earliest critical interval for assessing resistance to root rot caused by $F$. graminearum. Fisher's protected LSD gave the same differentiation of hybrids for AUDPC and for a critical time of disease assessment at 9 DAI (data not shown). Averaged over all three experiments, Pioneer Brand 3379 showed the least root rot 3 DAI, but by 6 DAI had exceeded that of LH119 $\times$ LH51 (Fig. 2). Noninoculated seedlings developed minor root disease due to spread of inoculum from inoculated roots within the same chamber (data not shown).

Inoculated seedlings had lower root dry weights than noninoculated seedlings in experiments 1 and 2, but not in experiment 3 (data not shown). Root dry weights ranged from $0.104 \mathrm{~g}(\mathrm{LH} 123 \times \mathrm{LH} 93$ and A6550 in experiment 1) to $0.219 \mathrm{~g}$ (LH119 
$\times$ LH51 in experiment 3) (Table 3). Shoot growth (AUSGC and shoot dry weight) was reduced significantly by inoculation with $F$. graminearum in experiment 1 but not in experiments 2 and 3 . In the latter two experiments, inoculation did not reduce shoot height compared with noninoculated seedlings even by 15 DAI, although hybrids differed in shoot height as early as 3 DAI (data not shown). AUSGC values ranged from 1,441 (Pioneer Brand 3378 in experiment 1) to 2,827 (A6550 in experiment 2) (Table 2). Shoot dry weights ranged from $0.094 \mathrm{~g}$ (Pioneer Brand 3378 in experiment 1) to $0.215 \mathrm{~g}$ (LH119 $\times$ LH51 in experiment 3) (Table 3). LH119 $\times$ LH51 consistently had the greatest root and shoot dry weights over all experiments, and had the greatest AUSGC for two of three experiments. Rankings of hybrids based on AUSGC, root dry weight, or shoot dry weight were less consistent than rankings of hybrids based on AUDPC (Tables 2 and 3).

Averaged over the three experiments, LH119 $\times$ LH51 and Pioneer Brand 3379 were the most resistant to infection by $F$. graminearum (mean AUDPC $=16.08$ and 20.42, respectively). LH119 $\times$ LH51 also had the greatest mean shoot growth, and mean root and shoot dry weights over all three experiments (Tables 2 and 3). Although LH123 $\times$ LH93 and A6550 were the most susceptible to $F$. graminearum (mean AUDPC $=35.25$ and 33.50, respectively) and had the lowest root dry weights, their mean shoot growth was exceeded only by that of LH119 $\times$ LH51.

AUDPC was negatively correlated with AUSGC $(r=-0.61,-0.38$, and -0.56 for experiments 1,2 , and 3 , respectively), with root dry weight $(r=-0.65,-0.50$, and 0.34 for experiments 1,2 , and 3 , respectively), and with shoot dry weight ( $r=$ $-0.68,-0.46$, and -0.54 for experiments 1 , 2 , and 3 , respectively). Pearson's correlation coefficients ranged from 0.83 to 0.95 for AUSGC and shoot dry weight, from 0.38 to 0.48 for AUSGC and root dry weight, and from 0.57 to 0.73 for root and shoot dry weights. All correlations were significant at $P=0.01$. The coefficient of variation $(\mathrm{CV})$ for root disease decreased with increasing DAI $(72 \%$ at 3 DAI to $35 \%$ at $15 \mathrm{DAI})$, while the $\mathrm{CV}$ for shoot height increased with increasing DAI (14\% at $3 \mathrm{DAI}$ to $22 \%$ at $15 \mathrm{DAI}$ ).

\section{DISCUSSION}

With this aeroponics system, genotypic differences in resistance to $F$. graminearum were observed among the nine hybrids screened. The aeroponics system also identified inherent differences among hybrids for shoot development (AUSGC), and for root and shoot dry weights. Chambers (5) suggested that both inherent genetic resistance and agronomic traits of a genotype be considered when searching for resistance to root rot. Some maize genotypes develop fine roots more readily than other genotypes and are better able to generate fine roots during moisture stress (5). LH119 × LH51 rapidly developed an extensive root system, compared with other hybrids tested, indicating it may withstand moisture stress more efficiently. This would be valuable in resistance to opportunistic pathogens like $F$. graminearum that attack plants under stress. However, consideration must be given to the artificial environment of the aeroponics system compared with field situations. Growth and development of aeroponically grown seed- lings differ from those of seedlings grown in a soil environment. The shoot/root ratio of seedlings is greater in the aeroponics system, which may affect disease progress and/or host resistance. For example, LH119 $\times$ LH51 and LH123 $\times$ LH93 are both reported to have vigorous root systems, but LH123 $\times$ LH93 had the lowest root dry weight in all three experiments while LH119 $\times$ LH51 had the greatest root dry weight.

Use of AUDPC or selecting a critical stage of development for disease assessment in screening for resistance would not

Table 2. Mean AUDPC and AUSGC (and rankings) for maize seedlings inoculated with Fusarium graminearum and grown in an aeroponics system ${ }^{\mathrm{a}}$

\begin{tabular}{|c|c|c|c|c|c|c|}
\hline \multirow[b]{2}{*}{ Hybrid } & \multicolumn{3}{|c|}{ AUDPC } & \multicolumn{3}{|c|}{ AUSGC } \\
\hline & Exp. 1 & Exp. 2 & Exp. 3 & Exp. 1 & Exp. 2 & Exp. 3 \\
\hline LH119 × LH51 & $13.25(1)$ & $19.25(1)$ & $15.75(1)$ & 1934 (1) & 2,677 (3) & $2,747(1)$ \\
\hline 3379 & $15.75(2)$ & $24.50(4)$ & $21.00(3)$ & $1802(4)$ & $2,379(8)$ & $2,480(3)$ \\
\hline 7997 & $22.25(4)$ & $20.50(2)$ & $25.00(7)$ & 1801 (5) & $2,812(2)$ & $2,360(4)$ \\
\hline LH136 × LH82 & $30.00(7)$ & $23.00(3)$ & $18.75(2)$ & $1563(8)$ & $2,631(5)$ & $2,342(5)$ \\
\hline DK667 & $15.75(2)$ & $27.75(5)$ & $29.25(8)$ & $1861(3)$ & $2,574(6)$ & $2,162(8)$ \\
\hline LH204 × LH212 & $23.25(5)$ & $29.00(6)$ & $21.75(4)$ & $1725(7)$ & $2,348(9)$ & $2,226(6)$ \\
\hline 3378 & $29.75(6)$ & $31.25(7)$ & $24.00(5)$ & $1441(9)$ & $2,559(7)$ & $2,161(9)$ \\
\hline A6550 & $41.25(9)$ & $34.50(8)$ & $24.75(6)$ & $1737(6)$ & $2,827(1)$ & $2,562(2)$ \\
\hline LH123 × LH93 & $34.50(8)$ & $42.00(9)$ & $29.25(8)$ & $1881(2)$ & $2,664(4)$ & $2,201(7)$ \\
\hline $\mathrm{LSD}^{\mathrm{b}}$ & 10.29 & 8.19 & 8.20 & 411 & 473 & 799 \\
\hline
\end{tabular}

${ }^{a}$ AUDPC $=$ area under disease progress curve of root rot (based on a 0 to 6 scale) plotted against days after inoculation (11). AUSGC $=$ area under shoot growth curve of shoot height plotted against days after inoculation. Each mean is the average of six inoculated seedlings from three replications per experiment and two samples per hybrid.

b Fisher's least significant difference at $P=0.05$.

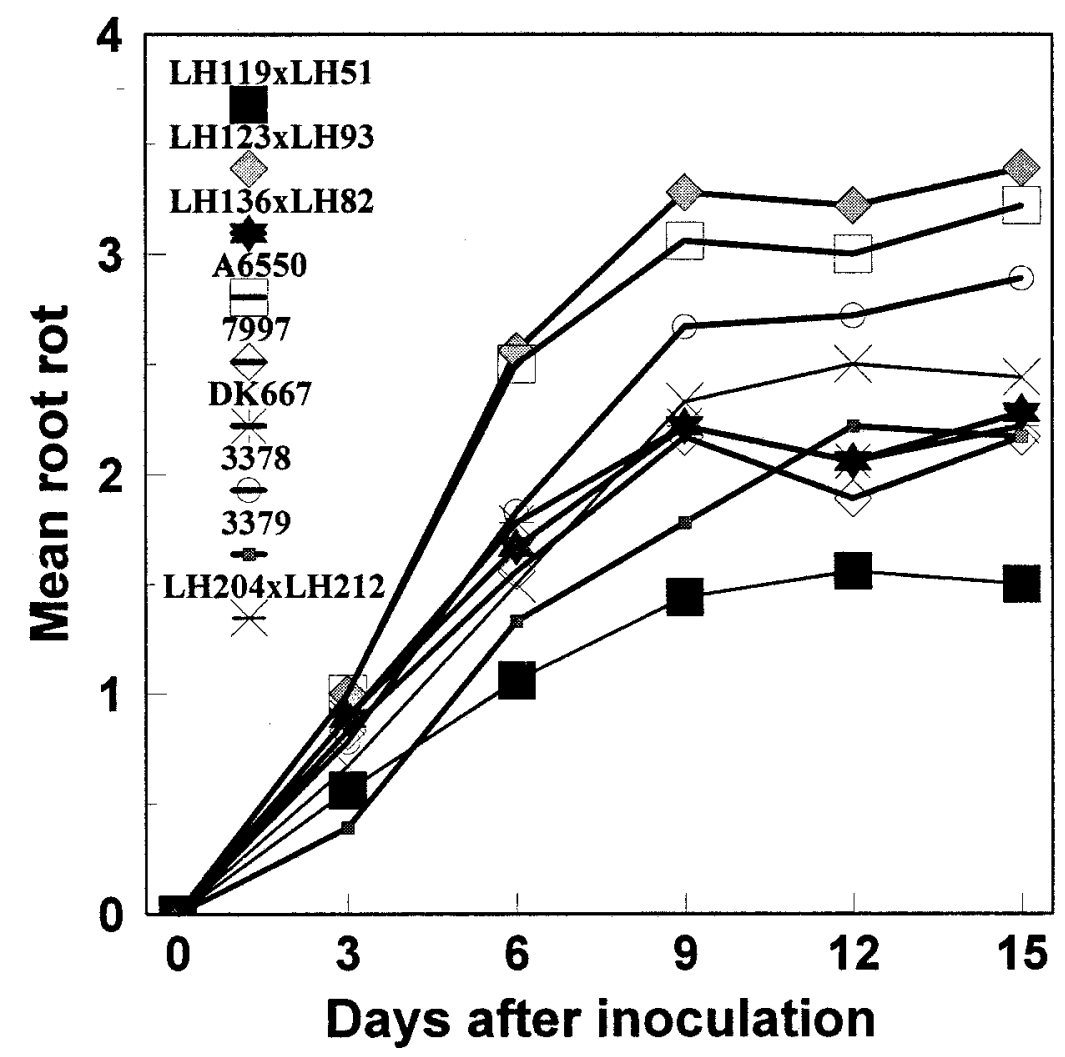

Fig. 2. Disease progress curves for root rot of nine maize hybrids inoculated with Fusarium graminearum and grown in an aeroponics system. Each measurement is the mean of 18 seedlings from three experiments, three replications per experiment, and two samples per hybrid. 
distinguish between a genotype with a high level of resistance initiated later in development from a genotype with early but slow-developing resistance. The aeroponics system enabled repeated measurements during development so that disease progress curves could be constructed. This provided the advantage of discerning how early resistance is expressed in genotypes. As a result, the greater resistance of LH119 $\times$ LH51 and Pioneer Brand 3379 was evident as early as 6 DAI. This expression of resistance may be valuable in overcoming seedling pathogens that have decreasing ability to infect maize seedlings as the plants develop. Hooker and Dickson (12) showed that inbreds and hybrids resistant to Pythium outgrew this seedling pathogen rapidly while susceptible lines took a longer time to overcome seedling infection. In the aeroponics system, root rot development was most rapid 3 to 9 DAI and decreased thereafter for all hybrids. No further seedling blight occurs by the third or fourth leaf stage when secondary roots are functional, although the fungus may remain in a latent phase within the plant (18). Disease progress curves also facilitate detection of a critical stage of disease assessment, which may simplify subsequent resistance screening by enabling disease assessment at one interval instead of making repeated measurements.

The major problem experienced with this aeroponics system was variation in results among experiments. Such variability is not uncommon when screening for resistance to seedling blights because of the sensitivity of these host-pathogen relationships to numerous factors. Mesterhazy (16) stated that variability of the pathogen and disposition of the host should be considered. Although temperature and light intensity in the greenhouse were not recorded, they varied among the experiments. Temperature affects many hostpathogen interactions $(6,13,22)$. The gray color of the chambers increased light absorption, raising interior chamber temperatures to above $30^{\circ} \mathrm{C}$ at times. Seedling vigor was probably enhanced by the warm and humid conditions in the chambers, resulting in increased resistance to $F$. graminearum. This is supported by evidence of greater shoot development in experiments 2 and 3 compared with experiment 1. Inoculation reduced shoot growth more in experiment 1 when temperatures were cooler than in experiments 2 and 3. Temperature and lighting fluctuations should be minimized to reduce variability in results.

Significant isolate-by-genotype interactions are also a consideration in resistance tests (16). Some researchers recommend using a single but highly aggressive isolate in screening for resistance, while others recommend a mixture of different isolates $(2,12,16,17,20)$. Although a single isolate was used for the duration of this experiment to avoid isolate-by-genotype interactions, variability between experiments from subculturing the isolate may have contributed to variation in results. Rao et al. (20) used resistant and susceptible checks when screening pea genotypes for resistance to common root rot by means of an aeroponics system. Such checks would help detect sources of variation (other than genotypic) in resistance screening.

The various pathogens associated with maize seed rots and seedling blights differ in their life cycles, survival mechanisms, and optimal conditions for growth and infection. The aeroponics system is a potentially valuable, simple, and rapid method for preliminary screening of genotypes for resistance to a specific seedling blight or root rot. It avoids many of the difficulties associated with studying soilborne diseases, e.g., non-uniform spatial distributions of inoculum in the soil and unknown interactions among inoculated pathogens and resident mycoflora. Disease progress curves can be calculated to detect differences in the rapidity of disease development or expression of resistance among host genotypes. Composition of the nutrient solution can be altered to study the impact of plant nutritional status on disease development. Misting duration and intervals can be varied to examine how differ-

Table 3. Mean root weight and shoot weight (and rankings) for maize seedlings inoculated with Fusarium graminearum and grown in an aeroponics system ${ }^{\mathrm{a}}$

\begin{tabular}{lccccccc}
\hline & \multicolumn{3}{c}{ Root dry weight $(\mathrm{g})$} & & \multicolumn{3}{c}{ Shoot dry weight $(\mathrm{g})$} \\
\cline { 2 - 4 } \cline { 7 - 8 } Hybrid & Exp. 1 & Exp. 2 & Exp. 3 & & Exp. 1 & Exp. 2 & Exp. 3 \\
\hline LH119 $\times$ LH51 & $0.183(1)$ & $0.213(1)$ & $0.219(1)$ & & $0.145(1)$ & $0.187(1)$ & $0.215(1)$ \\
3379 & $0.139(5)$ & $0.130(6)$ & $0.140(7)$ & & $0.124(3)$ & $0.139(7)$ & $0.181(2)$ \\
7997 & $0.113(7)$ & $0.152(4)$ & $0.132(8)$ & & $0.117(4)$ & $0.187(1)$ & $0.158(4)$ \\
LH136 $\times$ LH82 & $0.129(6)$ & $0.194(2)$ & $0.173(5)$ & & $0.100(7)$ & $0.181(3)$ & $0.152(5)$ \\
DK667 & $0.149(3)$ & $0.147(5)$ & $0.184(2)$ & & $0.130(2)$ & $0.160(4)$ & $0.123(8)$ \\
LH204 $\times$ LH212 & $0.151(2)$ & $0.129(7)$ & $0.182(3)$ & & $0.115(6)$ & $0.123(9)$ & $0.148(6)$ \\
3378 & $0.144(4)$ & $0.178(3)$ & $0.181(4)$ & & $0.094(9)$ & $0.151(5)$ & $0.143(7)$ \\
A6550 & $0.104(8)$ & $0.120(8)$ & $0.153(6)$ & & $0.098(8)$ & $0.149(6)$ & $0.168(3)$ \\
LH123 $\times$ LH93 & $0.104(8)$ & $0.117(9)$ & $0.123(9)$ & & $0.116(5)$ & $0.133(8)$ & $0.120(9)$ \\
LSD & 0.046 & 0.051 & 0.042 & & 0.049 & 0.067 & 0.101 \\
\hline
\end{tabular}

${ }^{a}$ Each mean is the average of six inoculated seedlings from three replications per experiment and two samples per hybrid.

${ }^{\text {b }}$ Fisher's least significant difference at $P=0.05$. ent moisture regimes affect host-pathogen interactions.

Potentially resistant genotypes selected with this method should be tested in a soil environment and under variable cultural conditions. LH119 $\times$ LH51 had the greatest resistance to root rot and the most extensive root system under the conditions of this experiment, and should be evaluated further. The intermediate resistance indicated in several hybrids (Pioneer Brand 3379, Pioneer Brand 7997, DK667, LH136 $\times$ LH82, and LH204 $\times$ LH212) may also provide sources of "additive" types of resistance.

\section{ACKNOWLEDGMENTS}

We thank Charlie Smyth for assistance in data analysis, and Emerson Nafziger for helping plan the research and review the manuscript.

\section{LITERATURE CITED}

1. Bacon, C. W., Hinton, D. M., and Richardson, M. D. 1994. A corn seedling assay for resistance to Fusarium moniliforme. Plant Dis. 78: 302-305.

2. Bai, G., and Shaner, G. 1994. Scab of wheat: Prospects for control. Plant Dis. 78:760-766.

3. Campbell, C. L., and Noe, J. P. 1985. The spatial analysis of soilborne pathogens and root diseases. Ann. Rev. Phytopathol. 23:129-148.

4. Carter, W. 1942. A method of growing plants in water vapor to facilitate examination of roots. Phytopathology 32:623-625.

5. Chambers, K. R. 1987. Ability of fungal isolates from maize and sorghum to infect roots and reduce seedling emergence of two maize hybrids. Plant Dis. 71:736-739.

6. Dickson, J. G. 1923. Influence of soil temperature and moisture on the development of the seedling-blight of wheat and corn caused by Gibberella saubinetii. J. Agric. Res. 13: 837-870.

7. Draganic, M. 1982. Reaction of local maize varieties to root rot (Gibberella zeae) based on conditions of artificial inoculation on nutritive agar (substrate). Zast. Bilja 33:313316.

8. Draganic, M., Viktorija, P., and Levic, J. 1984. Possibilities in protecting maize seed from Fusarium graminearum using fungicides. Zast. Bilja 35:101-106.

9. Hoagland, D. R., and Arnon, D. I. 1950. The water culture method for growing plants without soil. Calif. Agric. Exp. Stn. Circ. 347.

10. Hooker, A. L. 1956. Correlation of resistance to eight Pythium species in seedling corn. Phytopathology 46:175-176.

11. Hooker, A. L. 1956. Association of resistance to several seedling, root, stalk, and ear diseases in corn. Phytopathology 46:379-384.

12. Hooker, A. L., and Dickson J. G. 1952. Resistance to Pythium manifest by excised corn embryos at low temperatures. Agron. J. 44: 443-447.

13. Hoppe, P. E. 1949. Differences in Pythium injury to corn seedlings at high and low soil temperatures. Phytopathology 39:77-84.

14. Hoppe, P. E. 1951. A new technique for incubating seed corn in cold soil for disease tests. Phytopathology 41:747-751.

15. Marasas, W. F. O., Nelson, P. E., and Toussoun, T. A. 1984. Toxigenic Fusarium Species: Identity and Mycotoxicology. The Pennsylvania State University Press, University Park.

16. Mesterhazy, A. 1982. Resistance of corn to Fusarium ear rot and its relation to seedling resistance. Phytopathol. Z. 103:218-231. 
17. Mesterhazy, A. 1987. Selection of head blight resistant wheats through improved seedling resistance. Plant Breed. 98:25-36.

18. Molot, P. M., and Simone, J. 1967. Technique de contamination artificielle des semences de Mais par les Fusarioses. Rev. Zool. Agric. Appl. 1-3:29-32.

19. Pinnell, E. L. 1949. Genetic and environmental factors affecting corn seed germination at low temperatures. Agron. J. 41:562568.

20. Rao, A., Gritton, E. T., Grau, C. R., and Peterson, L. A. 1995. Aeroponics chambers for evaluating resistance to Aphanomyces root rot of peas (Pisum sativum). Plant Dis. 79: 128-132.

21. Shurtleff, M. C. 1980. Compendium of Corn Diseases. 2nd ed. American Phytopathological Society, St. Paul, MN

22. Smith, D. R., and White, D. G. 1988. Disease of corn. Pages 687-766 in: Corn and Corn Improvement. 3rd ed. G. F. Sprague and J. W. Wild, eds. American Society of Agronomy, Crop Science Society of America, Soil Science Society of America, Madison, WI.
23. Wagner, R. E., and Wilkinson, H. T. 1992. An aeroponics system for investigating disease development on soybean taproots infected with Phytophthora sojae. Plant Dis. 76:610614.

24. Windels, C. E., Kommedahl, T., Stienstra, W. C., and Burnes, P. M. 1988. Occurrence of Fusarium species in symptom-free and overwintered cornstalks in northwestern Minnesota. Plant Dis. 72:990-993.

25. Zobel, R. W., Tredici, P. D., and Torrey, J. G. 1976. Methods for growing plants aeroponically. Plant Physiol. 57:344-346. 